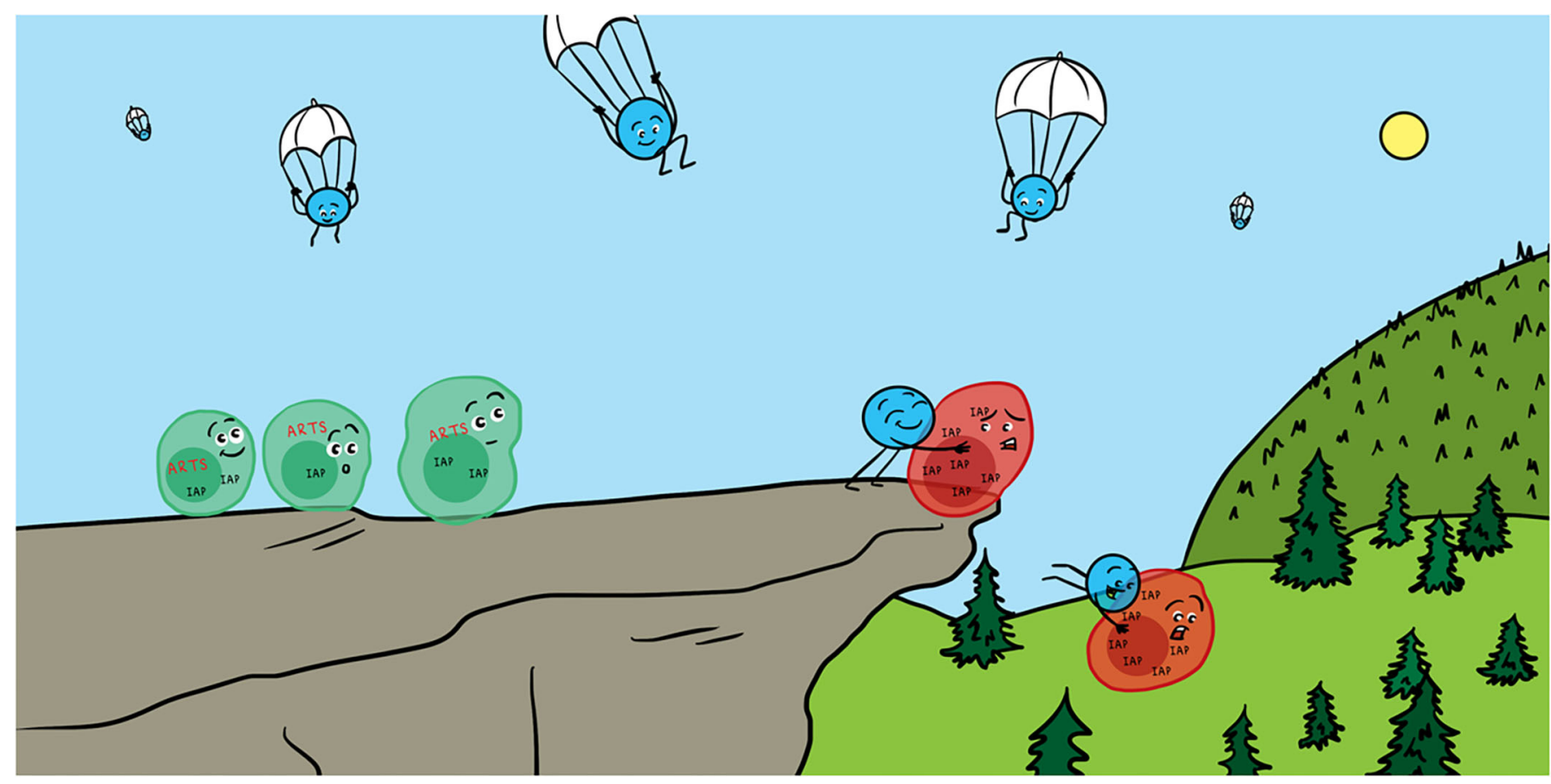

\title{
THE "ARTS" OF CELL DEATH IN SERVICE OF LIFE: HOW DO WE FORCE CANCER CELLS TO COMMIT SUICIDE?
}

\section{Sarit Larisch*}

Department of Biology and Human Biology, Faculty of Natural Sciences, University of Haifa, Haifa, Israel

\begin{tabular}{|l|l} 
YOUNG REVIEWERS \\
\\
DAVID \\
BEN-GURION \\
EDUCATION \\
CAMPUS \\
HEFER \\
VALLEY \\
AGES: 13-15
\end{tabular}

Every cell in our body contains a "self-destruction" program. This cell death is a critical process allowing replacement of damaged cells with healthy ones to prevent wide range of diseases. When the cell's death mechanism gets "stuck" and is not activated, cancer can result. In healthy cells there is a balanced system of proteins, some of which activate the normal death mechanism, and some of which inhibit this process. This is like the system of gas and brakes in a car. Researchers have found that cancer cells lack a protein, called ARTS, which is crucial for activating the cells' death mechanism. The lack of ARTS causes cancer cells to escape death and become "immortal." Small ARTS-like molecules have been discovered that can penetrate cancerous cells and reactivate the cell death program, effectively making the cancer cells "commit suicide." We envision that these ARTS-like molecules will provide novel therapy for cancer. 


\section{APOPTOSIS}

Is one of the main types of programmed cell death. It is a cellular process in which damaged or non-functional cells "commit-suicide" to be replaced by healthy functional cells, and provide a major defense against many diseases. A common feature of most types of cancers is their ability to escape apoptosis.

\section{CASPASES}

Proteins that help with the cellular death process by cutting up and breaking down essential proteins in the cell, leading to the cell's death.

\section{INHIBITOR OF} APOPTOSIS PROTEINS (IAPS)

Proteins that bind to caspases and thus inhibit, or prevent, unwanted cellular death.
In our bodies, about 300 million cells die every minute. About 50 billion cells die in our bodies every day. When cells die, new cells replace them. We can say that we are being renewed each and every day; almost being re-born, on a cellular level! Most cells die in a process called "apoptosis" (a-pop-to-sis), meaning "fall" in Latin. Indeed, old damaged cells that do not function properly "fall off" and die, and new cells arrive, keeping the body safe and making sure it operates in the best possible way. The process of apoptosis is so important and fundamental that it has been maintained throughout evolution, and happens in almost the same way in tiny microscopic worms, flies, mice, and rats ... all the way up to and including humans. Apoptosis is also called programmed cell death, since it is an organized, accurate sequence of events, in which every step drives the next step. Just like arranging dominos: once we push the first domino, the process runs step by step, from one step to the next, until the death of the cell. This is a natural method of cell death that keeps the body safe and properly functioning.

What does the apoptotic death of cells look like? First, each cell evaluates its situation, such as the level of damage to the cell, the cell's ability to fix its damage, and its ability to return to normal functioning. For example, if a cell has damage to its DNA, there are proteins whose job is to fix this. Once these proteins fail at their mission and the cell "understands" that it cannot fight the damage, the self-destruction mechanism of apoptosis is activated.

\section{HOW DOES THE APOPTOSIS WORK?}

In each cell there are proteins whose job is to cut up other proteins. These proteins are called caspases. These cutting proteins operate like Packman from the old computer game. Once they are activated, they multiply and chop up and digest all of the cell's contents, which results in the death of the cell. To keep these destructive proteins in check, there are other proteins called inhibitor of apoptosis proteins (IAPs). The job of the inhibitor proteins is to prevent the activity of the cutting proteins, to stop them from causing the unwanted death of cells.

When a signal happens inside the cell signaling that the cell is meant for destruction, the caspases will increase until they outnumber the inhibitor proteins. The caspases will cut up, break down, and package the broken-down cell content into bubbles of the membrane that wraps the cell (Figure 1). In the next step, the bubbles break off from the cells as tiny blobs containing the dead cell's content. These blobs will be taken up by other cells whose job is to clean up dead cells, and there will be no trace left of them. This is how cells die an apoptotic death [1].

It is important to note that the cell's decision to die is its way of supporting the entire organism. When a cell is not functioning well, 
Figure 1

Stages of apoptosis Apoptotic cells and nuclei undergo shrinking, blebbing of the membrane and packaging into apoptotic bodies that contain organelles, cytosol and nuclear fragments. Illustration created using Biorender.com.

\section{ARTS}

ARTS is a protein that is important for activating apoptosis and for suppressing cancer. ARTS is found in most cells but is lost in many types of cancers, which avoid apoptosis. ARTS activates apoptosis by breaking and neutralizing IAPs, releasing caspases to cut most proteins in the cells leading to its death.

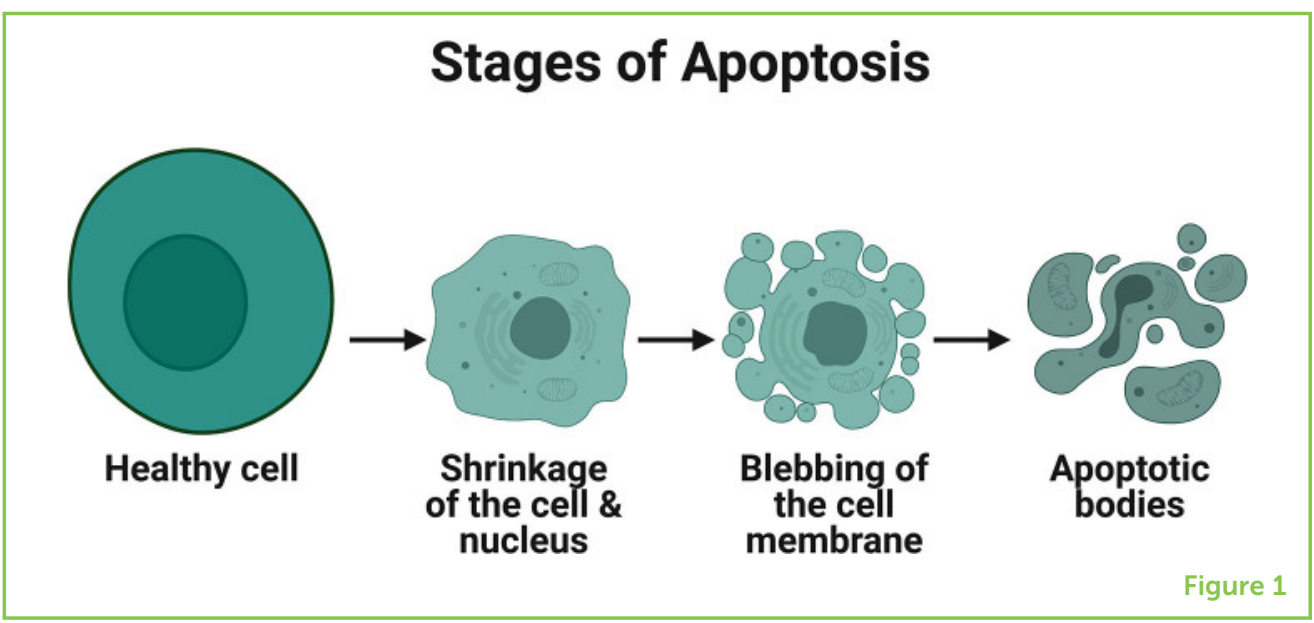

it can endanger other cells or the whole organism, so unhealthy cells will sacrifice themselves in order to save the entire body. Think of it this way-we know from Darwin's theory of evolution that the most well-adapted, strongest organisms will survive. Now we understand that the survival of the entire body depends on single cells that choose to sacrifice themselves for the good of all.

\section{WHEN APOPTOSIS GOES WRONG}

Since apoptosis is so important, you can probably imagine that an error in this mechanism could result in a wide variety of diseases. On the one hand, diseases might be caused by an excess of cellular death. In diseases, such as Alzheimer's or Parkinson's, there is too much death of brain cells. On the other hand, in some diseases, like most types of cancer, the cellular death processes are blocked. Healthy cells find ways to bypass the cellular death process and acquire "immortality," becoming cancerous cells that multiply without control. Therefore, understanding the cellular processes that lead to apoptosis might help us to find new drugs for degenerative brain diseases and for many kinds of cancer [1].

\section{ARTS: A CANCER SUPPRESSING PROTEIN}

In our lab at the University of Haifa, we study the mechanisms that allow for cellular death, and how errors in these processes drive healthy cells to become cancerous. We focus on a protein we discovered and named ARTS [2]. ARTS operates at the beginning of the series of processes that lead to the cell's death. ARTS initiates apoptosis by binding to and neutralizing the IAPs, making them break down and disappear [3]. This means that ARTS basically operates by releasing the "brakes" of the cell, allowing the caspases to cut up all the proteins in the cell, which will result in its death (Figure 2). 
Figure 2

The role of the ARTS protein in activating apoptosis in cells. (A) ARTS (red) is found in all healthy cells. The IAPs (gray) bind to and inhibit the activity of the caspases (yellow). This binding prevents the unwanted death of the cell. (B) If the cell is damaged and cannot function, a signal will be activated to start apoptosis. As a result, the ARTS proteins will bind to the IAPS. This binding will result in the release of the caspases. The caspases can then cut and break down the cell's proteins, and this will result in the cell's death by apoptosis.
A
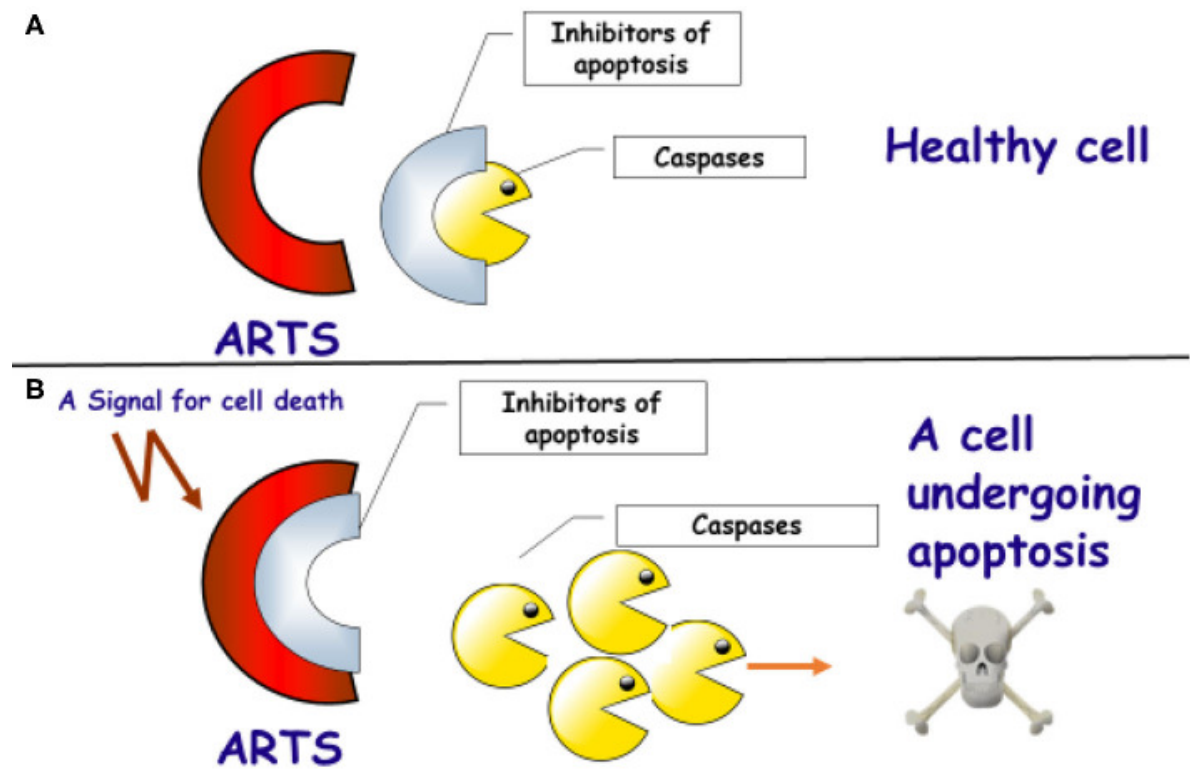

Figure 2

One proof for the importance of the ARTS protein in the activation of apoptosis is cells that lose the ARTS protein have a decreased ability to undergo apoptosis, and might become cancer cells. Indeed, mice that were engineered to be born without the ARTS protein developed several kinds of cancer, mainly blood cancers like lymphoma and leukemia [4]. Additionally, in studies of samples from patients with different kinds of cancers, we found that the ARTS protein was missing in most of the samples [5]. This means that the ARTS protein acts as a cancer inhibitor protein. Its presence in cells allows damaged cells to be eliminated by apoptosis (Figure 2), and its absence allows the multiplication of damaged cells and their transformation into cancer cells.

Today's most common anti-cancer treatments, chemotherapy and radiation, act by deliberately activating the cellular "suicide" mechanism -stimulating the cancer cells to undergo apoptosis. But, these treatments have big problems with side effects because they also damage healthy cells Patients can also develop resistance to chemotherapy drugs. So, how do we use our knowledge about ARTS to develop new anti-cancer drugs that will make cancer cells "commit suicide"?

\section{SMALL ARTS-LIKE MOLECULES TO THE RESCUE!}

Many types of cancer escape cell death by silencing the ARTS protein and increasing the amount of the IAPs, which inhibit cell death. It seems like a simple solution could be to return ARTS into the cancer cells that lost it. This would allow those cells to break down the IAPs and cause the cells to undergo apoptosis. The problem is that the ARTS protein is big, and it cannot easily cross the cell membrane to 
SMALL ARTS-LIKE

\section{MOLECULES}

Very small units of non-biological material that imitate the activity of ARTS inside cells. These molecules penetrate the cell's membrane and bind to the IAPs. Binding releases the caspases, which then cut and break down the cancer cell, leading to its death. get into the cells. But we found a solution! We identified some very small molecules that imitate the activity of ARTS and that can penetrate the cell's membrane. These small ARTS-like molecules can inhibit the IAPS exactly like ARTS does, therefore making the cancer cells undergo apoptosis [6].

You are probably wondering, "what about the healthy cells? Would not the ARTS imitators penetrate them as well?" The answer is that the ARTS-like molecules do target IAPs in both healthy and cancerous cells. But the cancer cells are missing ARTS and they are expressing high levels of IAPs. The cancer cells are actually dependent on the high levels IAPs to keep them alive. You can imagine it like standing on a high cliff-the cancer cells are standing there on the edge of the cliff, but their state is very unstable. A relatively small amount of small ARTS-like molecules, which lowers the levels of IAPs in the cancer cells just a little bit, will make the cancer cells fall off the cliff to their deaths. In contrast, healthy cells contain ARTS and have relatively low levels IAPs, so these cells are stable-they are not standing on a cliff, and therefore much larger amounts of small ARTS-like molecules are needed to kill them. This difference between cancer cells and healthy cells can allow us to treat patients with a specific concentration of small ARTS-like molecules that will kill cancer cells but will not harm the healthy cells. We hope that these small ARTS-like molecules that we are developing in our lab will become anti-cancer drugs that force cancer cells to undergo apoptosis while maximally reducing the side effects of cancer treatment.

\section{In a Nutshell}

Programmed cell death, apoptosis, is an essential biological process that gets rid of damaged and non-functioning cells which could endanger the health of the body. Therefore, apoptosis acts as defense against the emergence of a variety of diseases. Cells which lose their ability to die can transform into cancer cells. ARTS, is a protein that plays a major role in activating the apoptosis program. Cancer cells can escape apoptosis by losing ARTS. Small molecules which imitate ARTS can penetrate cancer cells substituting the ARTS protein and re-enforcing the activation of apoptosis selectively in cancer cells. These molecules could become novel and promising anti-cancer drugs.

\section{FUNDING}

This work was supported by funds by ISF (Israel Science Foundation), Grant \#1264/06 and 822/12 and INCPM-ISF grant \#2376/15, the Charles Wolfson Charitable Trust, England, and by a generous award from the Hymen Milgrom Trust . 


\section{ACKNOWLEDGMENTS}

We thank Ruqaia Abbas for excellent work in preparing the illustration in Figure 1.

\section{REFERENCES}

1. Fuchs, Y., and Steller, H. 2011. Programmed cell death in animal development. Cell 147:742-58. doi: 10.1016/s0092-8674(00)81873-5

2. Larisch, S., Yi, Y., Lotan, R., Kerner, H., Eimerl, S., Tony Parks, W., et al. 2000. A novel mitochondrial septin-like protein, ARTS, mediates apoptosis dependent on its P-loop motif. Nat. Cell Biol. 2:915-21. doi: 10.1038/35046566

3. Edison, N., Curtz, Y., Paland, N., Mamriev, D., Chorubczyk, N., Haviv-Reingewertz, T., et al. 2017. Degradation of Bcl-2 by XIAP and ARTS promotes apoptosis. Cell Rep. 21:442-54. doi: 10.1016/j.celrep.2017.09.052

4. Garcia-Fernandez, M., Kissel, H., Brown, S., Gorenc, T., Schile, A. J., Rafii, S., et al. 2010. Sept4/ARTS is required for stem cell apoptosis and tumor suppression. Genes Dev. 24:2282-93. doi: 10.1101/gad.1970110

5. Elhasid, R., Sahar, D., Merling, A., Zivony, Y., Rotem, A., Ben-Arush, M., et al. 2004. The mitochondrial pro-apoptotic ARTS protein is lost in the majority of Acute Lymphoblastic Leukemia patients. Oncogene 23:5468-7. doi: 10.1038/ sj.onc. 1207725

6. Mamriev, D., Abbas, R., Klinger, F. M., Kagan, J. K. N., Weidenfeld, K., Sheppard, D., et al. 2020. A small-molecule ARTS mimetic promotes apoptosis through degradation of both XIAP and Bcl-2. Cell Death Dis. 11:483. doi: 10.1038/ s41419-020-2670-2

SUBMITTED: 24 November 2020; ACCEPTED: 01 February 2021; PUBLISHED ONLINE: 01 April 2021.

EDITED BY: Idan Segev, Hebrew University of Jerusalem, Israel

CITATION: Larisch S (2021) The "ARTS" of Cell Death in Service of Life: How Do We Force Cancer Cells to Commit Suicide? Front. Young Minds 9:633011. doi: 10. 3389/frym.2021.633011

CONFLICT OF INTEREST: The author declares that the research was conducted in the absence of any commercial or financial relationships that could be construed as a potential conflict of interest.

COPYRIGHT () 2021 Larisch. This is an open-access article distributed under the terms of the Creative Commons Attribution License (CC BY). The use, distribution or reproduction in other forums is permitted, provided the original author(s) and the copyright owner(s) are credited and that the original publication in this journal is cited, in accordance with accepted academic practice. No use, distribution or reproduction is permitted which does not comply with these terms. 


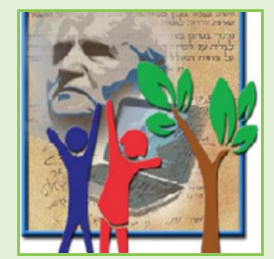

\section{YOUNG REVIEWERS}

DAVID BEN-GURION EDUCATION CAMPUS HEFER VALLEY, AGES: 13-15

We are eighth and ninth grade students learning in the Science and Technology reserve class at Kfar Monash in Israel.

\section{AUTHOR}

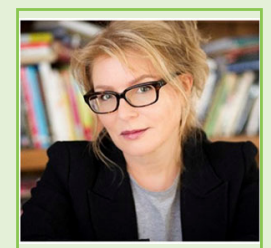

\section{SARIT LARISCH}

I am a Professor of Molecular Biology and Cancer Research at the University of Haifa. Israel. I am very happy in the profession I chose and grateful for being able to do research as my occupation. I love listening to music (rock, progressive rock, or any other music that causes me to have goosebumps on my skin). I have been a vegetarian for most of my life and feel very connected to animals, especially dogs and cats. I am also a "bookworm" (-), just wish I had more time to read. *saritlarisch@gmail.com; slarisch@univ.haifa.ac.il 